\title{
ICT Technologies in Optimization of Machines Movement at Open-Pit Coal Mine
}

\author{
Milos IVANOVIC, Dobrila SKATARIC
}

\begin{abstract}
Auxiliary machinery is used at the open-pit coal mine (machines: bulldozers, trench excavators, pipe-laying machines,...) for performance of auxiliary work (excavation, construction of route, ....) in order to provide an uninterrupted operation of the basic machinery for excavation of waste rock and coal. Machines are moving from one area of the open-pit to another. Movement of machines along the open-pit is limited space-wise by conveyor belts serving for conveyance of waste rocks and coal, including other natural obstructions (steep slopes, mud, water). These obstructions affect the open-pit machines' length of trajectory, duration of movement and consumption of fuel. Observing the said problem, a model for optimizing the "movement" of open-pit auxiliary machinery has been developed and applied with ICT, namely GPS/GPRS and appropriate software solution, as presented herein. Model determines the "shortest" path of the machine to the job which can result in significant fuel savings and reducing failures of machines.
\end{abstract}

Keywords: auxiliary machinery; ICT; GPS/GPRS technologies; model for optimizing; optimum route; open-pit coal mine; shortest path; software solution

\section{INTRODUCTION}

Auxiliary machinery (hereinafter referred to as machines) is used at the open-pit coal mine (machines: bulldozers, trench excavators, pipe-layers, ...) for performance of auxiliary works (excavation, relocation of conveyor belts, workmen transport, ...) in order to provide an uninterrupted operation of the basic machinery for excavation of waste rock and coal, Fig. 1. and Fig. 2.

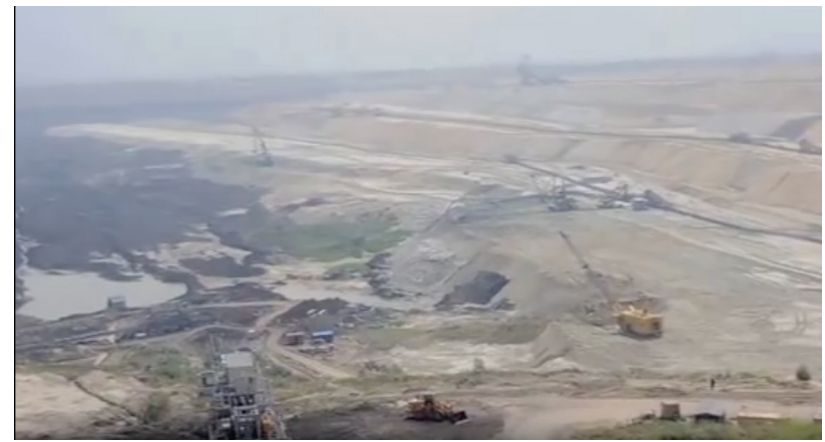

Figure 1 Open-pit coal mine with basic and auxiliary machinery and conveyor belts

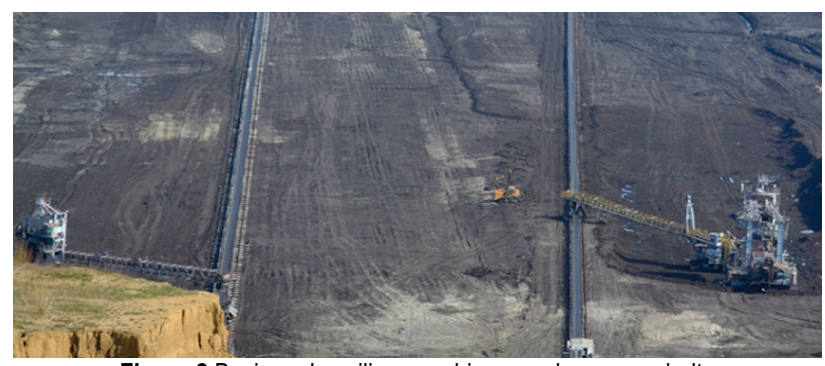

Figure 2 Basic and auxiliary machinery and conveyor belts

Machines are moving from one area of the open-pit to another. Movement of machines along the open-pit is limited space-wise by conveyor belts serving for conveyance of waste rocks and coal, including other natural obstructions (steep slopes, landslides, mud, water). These obstructions affect the open-pit machines' trajectory length, duration of movement and consumption of fuel.

With a view to optimize movement of machines along the open-pit, optimization of their movement has been approached. By optimization it can be achieved that machine from point $\mathrm{A}$ (from one area of the open-pit) "reaches" point B (another area of the open-pit) by the shortest route, or in other words "optimum route" taking into account any obstruction and possibilities of movement. In order to resolve the optimization, a model for optimizing and developed software application has been applied.

\section{OPTIMIZATION MODEL}

For movement of machines along the open-pit, route marking is performed subject to obstructions and possibilities of movement along the open-pit. Routes can be located below and above conveyors, to the left or to the right from the conveyors and around conveyors at the open-pit. In order to enable a machine to "reach" one area of the open-pit from another, it is possible to move either along these marked routes which are mostly parallel to conveyor belts or arranged around them, or along the other marked routes of the open-pit. For the purpose of maintenance, the open-pit machine "goes" to maintenance workshop. It is then also that the machines move along the marked way. Fig. 3 represents "current positions" of the basic and auxiliary machinery (with waste-rock and coal conveyor belts) at the open-pit coal mine "Drmno". Fig. 4 represents the marked routes.

With a view to resolve optimization of the machines movement along the open-pit, all marked routes and all "nodes" (all junctions, passages below and above the conveyors, redirection of routes) represent a NETWORK of routes with "nodes", from node 2 to $n$ (node 1 is a machine at any position), Fig. Distance from node $n$ to node $n \pm 1$ is defined in running metres, which is represented in Fig. 4 and in Tab. 1. Positions of machines/vehicles are monitored by GPS/GPRS technologies in real time, Fig. 3. By combining Fig. 3 and Fig. 4, it is possible to know the position of each machine in the real time against the node and $n$, the optimum route is calculated for each machine (from point A to B) it is node 1). Software solution Machine Trajectories has been developed for this purpose, and the GPS/GPRS enables "current position" of the open-pit machine, while the developed software solution defines the machine distance (node 1) from the nearest node $n$. 


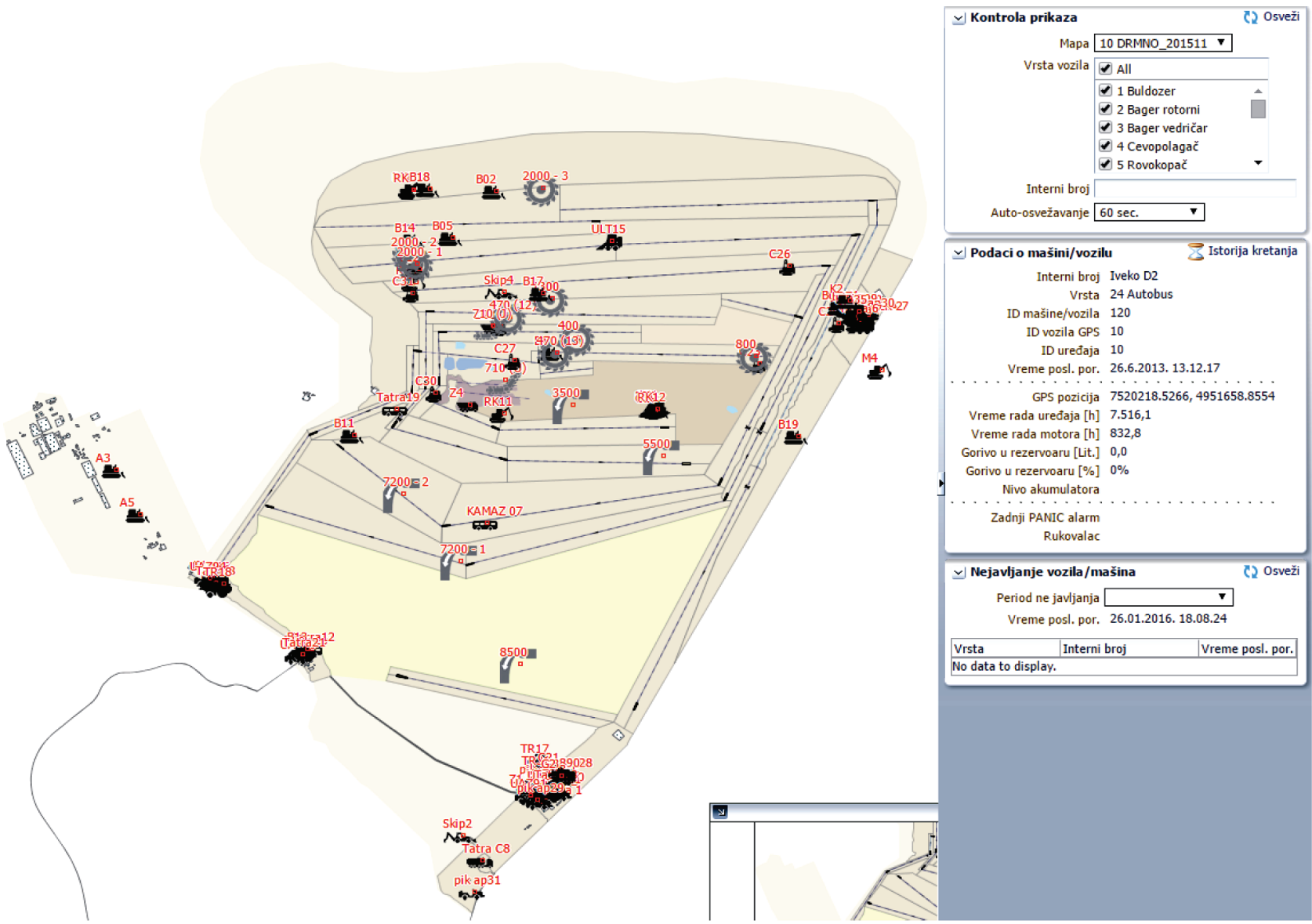

Figure 3 Monitoring positions of basic and auxiliary machinery by GPS/GPRS (with waste-rock and coal conveyor belts)

Table 1 Network of routes with "nodes"

\begin{tabular}{|c|c|c|r|}
\hline Node & GPS/GPRS coordinates of nodes & $\begin{array}{c}\text { From node } \\
\text { to node }\end{array}$ & $\begin{array}{c}\text { Length } \\
(\mathrm{m})\end{array}$ \\
\hline 2 & $7518719.98 ; 4952593.73$ & $\overline{23}$ & 793,0 \\
\hline & & $\overline{242}$ & 1837,0 \\
\hline & $7518052.17 ; 4953021.49$ & $\overline{243}$ & 1610,0 \\
\hline 3 & 754 & 800,0 \\
\hline & $\ldots$ & $\overline{357}$ & 300,0 \\
\hline 4 & $\ldots$ & $\overline{45}$ & 270,0 \\
\hline & $75491.76 ; 4953689.89$ & $\overline{448}$ & 1295,0 \\
\hline$\ldots$ & $7521249.60 ; 4955431.93$ & $\overline{6566}$ & 1000,0 \\
\hline 65 & \multicolumn{2}{|c|}{} \\
\hline 66 & & & \\
\hline
\end{tabular}

Software application Machine Trajectories determines optimum (shortest) trajectories of machines towards jobs position at the open-pit. Basic principles are "one machine for one job" and "any job can be performed by any machine from given sets" (in database Jobs and Machines). Here, one "job" refers to job for one machine.

Criterion for optimum route is the minimum length of the route. Software application Machine Trajectories joins machines and jobs into machine-job couples for realization of route based on the shortest distances from each machine and each Job. As a result, the software application provides solutions using the procedures I, II and III.

Fig. 5 represents the basic model for determining the shortest-optimum movement of machine $\mathrm{Mi}$ to job $\mathrm{Jj}$, where:

$-\overline{k, k \pm n}=\overline{k \pm n, k}$, represents the distance (route length) from node $k$ to $k \pm n(n=1,2, \ldots, m)$, i.e. from $k \pm n$ to $k$, $-M i$, represents positions of machines available for jobs

\section{$J$,}

$-J$, represents jobs,

- $\overline{M i, k}$, represents distance from machine $i$ to node $k$, or to $k \pm n$,

- $\overline{J j, k}$, represents distance from job $j$ to node $k, k \pm n$.

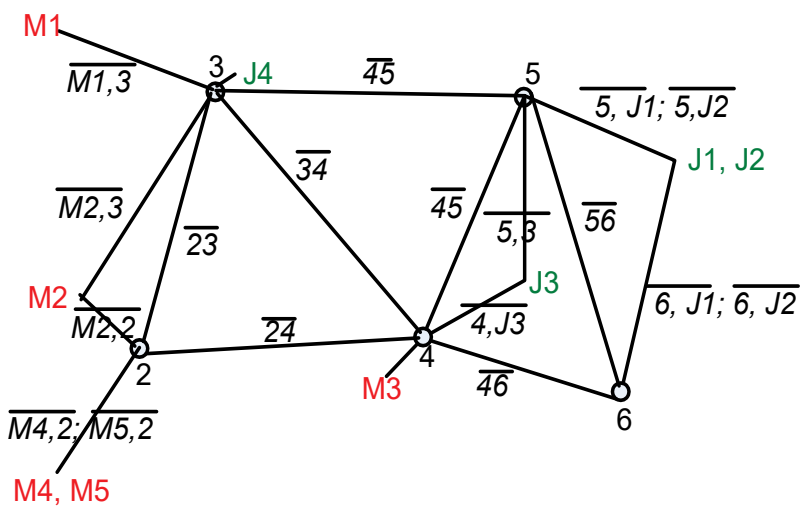

Figure 5 Routes, nodes, machines, jobs

For example, machine $M 3$ goes to the job $J 1$ via node 5 (node 5 , job $J 1$ ), or 6 (node 6 , job $J 1$ ), or 6 and 5 (node 6 and 5 job $J 1$ ), while it goes to the job $J 4$ via node 4 or 3 , or nodes 4,5 and 3 . Depending on the length of routes $\overline{46}$ and $\overline{6 J 1}$, or $\overline{45}$ and $\overline{5 J 1}$, or $\overline{46}$ and $\overline{65}$ and $\overline{5 J 1}$, the software application MachineTrajectories determines the shortest-optimum distance of $M 3$ to the job $J 1$. 


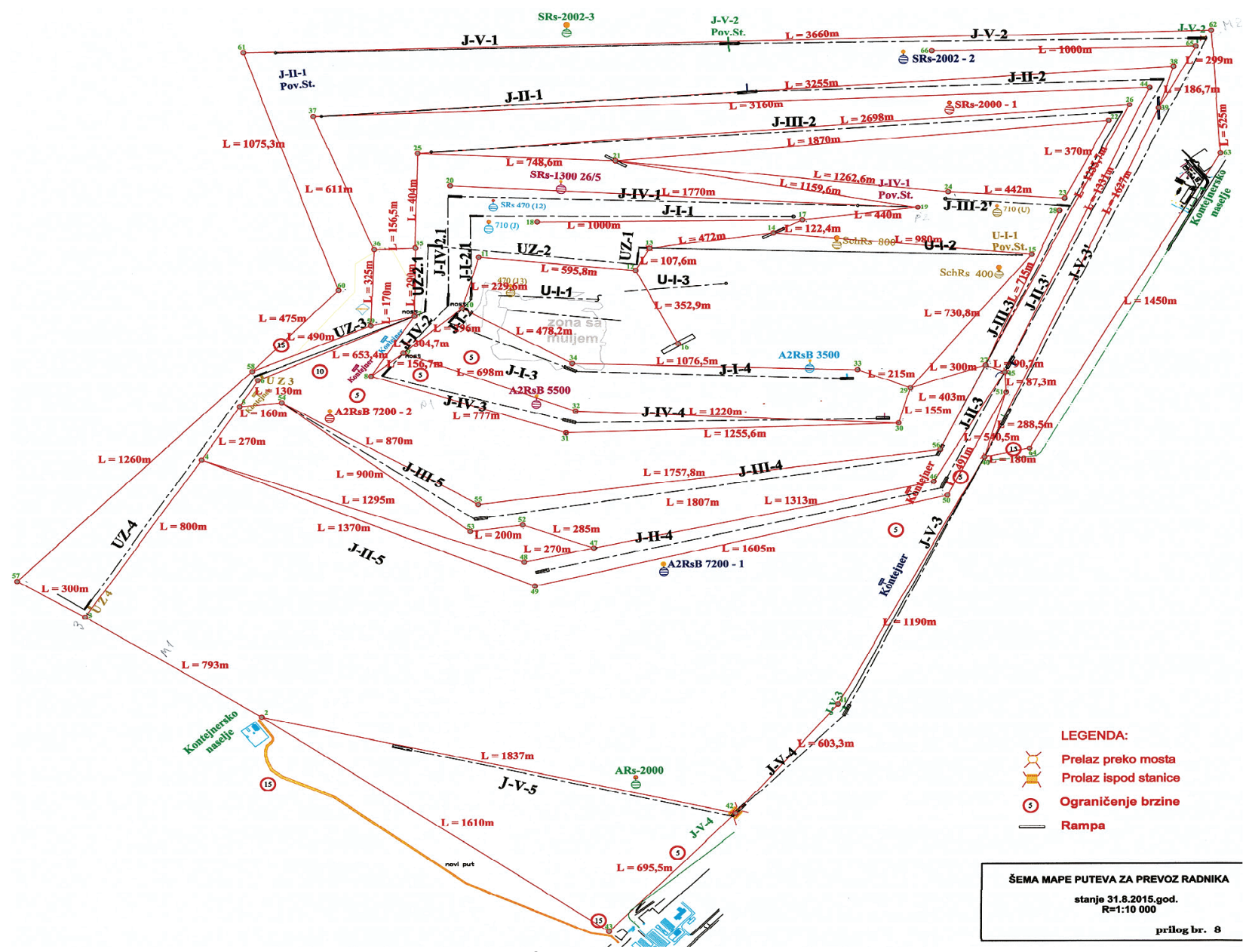

Figure 4 Open-pit routes and nodes network

Machines $M 4$ and $M 5$ are at the same location, jobs $J 1$ and $J 2$ are at different location. At its location, two machines are necessary and two jobs are displayed due to the software application principle "one machine for one job". The shortest-optimum route from machine $M i$ to the job $J j$ is determined according to the principle "one machine for one job".

However, if there is more than one machine of the same type available for the job which can be done by those machines, the nearest one will be engaged. But, if there is more than one machine of the same type available at different locations for the same job, or various jobs at different locations, then the trajectory of one machine for each job is determined. Then the other machine for the same jobs, and so on. "one machine for one job". Finally, route lengths are summed up according to procedures I, II and III.

Basic results of Machine Trajectories are optimum routes of machine-job couples. Software application joins machines and jobs into machine-job couples for the needs of the travel realization based on the shortest distances between each machine and each job. As a result, the software application provides three solutions according to procedures I, II and III (selected by user- open-pit dispatcher).

Procedure I "Couple selection": It starts with selection of machine-job couple having the shortest distance between them, then the previous couple is excluded from consideration and the next couple having the shortest distance between them is selected, etc. Number of trajectories $(T R)$ for realization is $T R=\min (M, J)$, where $M$ represents number of machines and $J$ represents number of jobs.

Procedure II "Partner selection": Partner from minority set (jobs/machines) selects a close partner (machine/job). This procedure provides solution for one of the two following cases:

- Case A - Number of available machines which is greater than number of jobs. For each job $\mathrm{j}$ (under sequence from $J o b$ ) the closest machine $i_{m}$ is determined which becomes unavailable in terms of other jobs.

- CaseB - Number of available machines which is less than or equal to the number of jobs. Each machine $i$ (under sequence from Machines) is accompanied by the nearest job $J_{m}$ which becomes covered in terms of other machines.

In procedure II, the first partner from minority set performs selection and has an advantage against others from the inlet set ("Job" database or "Machines" database).

Procedure III Dictated solution: Third solution is dictated by the user of software application Machine Trajectories through inlet sequence of machines in "Machines" database and jobs in "Job" database. The first machine from "Machines" goes to the first job from "JOB", the second one to the second, etc.

Software application Machine Trajectories provides lengths for all three solutions. Movements from one adopted solution are realized. 
Following adoption of one out of three solutions, openpit dispatcher notifies (during a "follow-up meeting") machine operator-driver on optimum route for movement of his machine to the job location.

Example of algorithm and software application with results from the open-pit is presented in chapter 3 "Example".

Dispatcher-user (exploitation manager) uses the software Machine Trajectories in order to schedule the engagement of machines for certain jobs during a scheduled period of time (shift or 24 hours, daily assignment of machines) as well as for a shorter period of time, as needed (emergency situation). One activation of software application is performed for one type of jobs, for example, jobs performed by bulldozers. It is necessary to prepare new data and to activate software application for a new type of jobs, for example, a job for pipe laying machines.

In practice, there are some situations deviating from the basic principles of the software application "one machine for one job" and "any Job can be performed by any machine from the given sets". By providing particular inlet data of the software application, the following situations are also resolved:

- One machine for two jobs on the same shift - It is resolved by scheduling the machine for the first job, while for the second job the software application is used again (just like for an emergency situation).

- For one (bigger) job it is necessary to engage more than one machine - It is resolved by registering more than one job at a given location (splitting the jobs into "portions", one "job" is "portion" of job for one machine).

- More than one different individual jobs - It can be resolved by a single use of software application; if machines in "Machine" database and jobs in "Jobs" database are adequate in terms of sequence, the first machine is adequate for the first job, the second machine for the second job, etc., the same as in dictated solution.

Trajectory of vehicle transporting the operators of selected available machines Locations of machines are entered into "Machines" database at sequence determined by dispatcher from the map, and the first location is vehicle departure location. Locations of machines are entered into "Jobs" database at the same sequence from the first location, and the last one is the location of the vehicle return. As a result, the software application provides optimum routes of vehicles between machines' locations, which is "dictated solution" in the software application results.

Database:

NETWORK containing data on routes network for software application:

- Title - arbitrary text up to 50 characters

- $K_{\text {node }}-$ the last numeration, for one greater than the total number of nodes

- For each node the ordinal number of node icv is provided (between 2 and $K_{\text {node }}$ ) and number of adjacent nods $n s c \geq 2$
- For nsc of nodes: ordinal number and movement indicator $>0$ from the node to adjacent node.

MACHINES containing data on machines for software application:

- Nmas - number of available machines

- For each available machine, the following is provided: Alphanumeric code of machine (from "machines" database, Fig. 6).

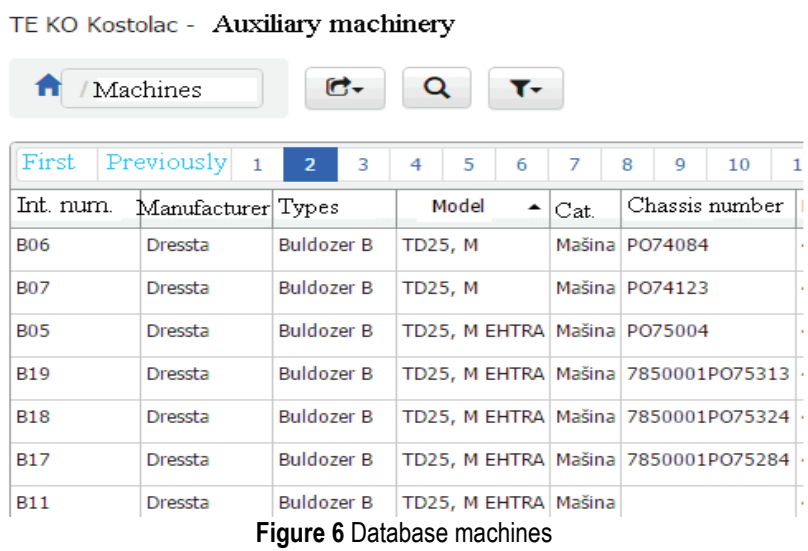

- Number of nodes adjacent to machine location $\geq 1$.

- For each adjacent node: ordinal number and movement indicator (route length) from the machine $\geq 0$.

- Data on available machines in "Machines" database must be adequate for the type of jobs in "Job" database, Fig. 7.

JOB containing data on jobs from the job Order

- $\quad N_{\text {last }}$ - total number of the same type of jobs

- For each $N_{\text {last }}$ of jobs, the following is provided: $N s c p$, number of nodes adjacent to the job location $\geq 1$

- For Nscp of nodes: node ordinal number and movement indicator (route length) from the node to the job $\geq 0$.

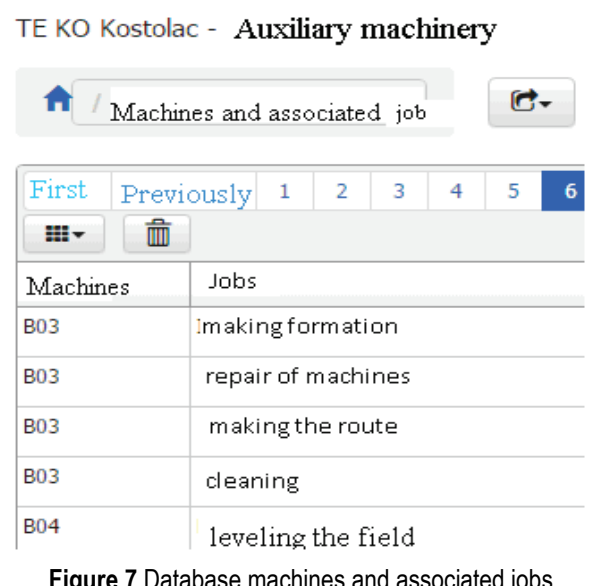

Software application results:

- This database contains intermediate results and main (final) results of software Machine Trajectories application.

- The software application title is determined by its user 


\section{EXAMPLE}

In compliance with applicable software, including machines, Fig. 2, and the routes network, Fig. 3, (they are shown here separately, but normally they are shown in one screen), procedure of determining the shortest optimum route is presented from machine (and machines) position to job (jobs), one machine for one job, according to procedures I, II and II (mentioned herein above). Pursuant to that, the shortest-optimum route is determined for all machines and all jobs.

Jobs from database are assigned, available machines are taken from machines database and the network is selected from the network database:

NETWORK (Tab. 1)

\begin{tabular}{|c|c|c|c|c|c|c|c|}
\hline Node & Length & Node & Length & Node & Length & Node & Length \\
\hline 3 & 793.0 & 42 & 1837.0 & 43 & 1610.0 & & \\
\hline $\begin{array}{l}33 \\
4 \\
44\end{array}$ & 800.0 & 57 & 300.0 & 2 & 793.0 & & \\
\hline $\begin{array}{l}5 \\
53\end{array}$ & 270.0 & 48 & 1295.0 & 49 & 1370.0 & 3 & 800.0 \\
\hline 6 & 130.0 & 54 & 160.0 & 4 & 270.0 & & \\
\hline $\begin{array}{l}64 \\
642\end{array}$ & 1450.0 & 62 & 525.0 & & & & \\
\hline $\begin{array}{l}40 \\
652\end{array}$ & 180.0 & 63 & 1450.0 & & & & \\
\hline $\begin{array}{l}66 \\
661\end{array}$ & 1000.0 & 63 & 299.0 & & & & \\
\hline
\end{tabular}

\section{JOB}

- Job 1: Construction of route, position JIV3/Middle, Fig. 4.

- Job 2: Cleaning, position JIV1/R(right)-end

- Job 3: Cleaning, position JI4/R-end

\section{MACHINES}

- Machine B03 bulldozer TD25H, position Containers area

- Machine B05 bulldozer TD25ME, position JV2/JV3.

- Machine A3 bulldozer TD40E, position JII1/L(lefet)end

RESULTS: the shortest distances between each machine and each job, Fig. 8.

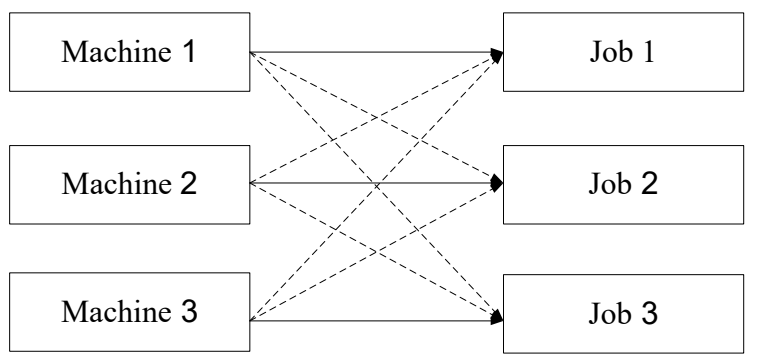

Figure 8 The shortest distances between each machine and each job

Machine Mi-job J1:

Machine B03-TD25H, position Containers area

- Job 1 Construction of route, position JIV3/middle

- Optimum route having length of $2935 \mathrm{~m}$ across nodes: 134567867
Machine B05, position JV2/JV3,

- Job 1 Construction of route, position JIV3/middle

- Optimum route having length of $4732 \mathrm{~m}$ across nodes: 16263644051452729303167

Machine A3, position JII1/L-end

- Job 1 Construction of route JIV3/middle

- Optimum route having length of $1739 \mathrm{~m}$ across nodes: 13736357867

\section{Machine Mi-job J2:}

Machine B03, position Containers area

- Job 2 Cleaning JIV1/R-end

- Optimum route having length of $4856 \mathrm{~m}$ across nodes: 345673525211967

Machine B05, position JV2/JV3,

- Job 2 Cleaning JIV1/D-end

- Optimum route having length of $5195 \mathrm{~m}$ across nodes: 162636440514527291514171967

Machine A3, position JII1/L-end

- Job 2 Cleaning JIV1/R-end

- Optimum route having length of $3080 \mathrm{~m}$ across nodes: 137363525211967

Machine Mi-job J3:

Machine B03, position KonNaselje

- Job 3 Cleaning JI4/R-end

- Optimum route having length of $4985 \mathrm{~m}$ across nodes: 134566789103430293367

Machine B05, position JV2/JV3,

- Job 3 Cleaning JI4/R-end

- Optimum route having length of $3186 \mathrm{~m}$ across nodes: 162636440514527293367

Machine A3, position JII1/L-end

- Job 3 Cleaning JI4/R-end

- Optimum route having length of $3790 \mathrm{~m}$ across nodes: 1373635789103430293367

Result: shortest routes for the system. Result of optimization procedures I, II and III.

I procedure "couple selection": solution for trajectories system, Tab. 2.

Length matrix: coupling procedure.

Machine B03: position Containers area $400 \mathrm{~m}$ to node 3 length $4856 \mathrm{~m}$ to job 2 Cleaning, position JIV1/R-end 0 m to node 19 . By route 3456735252119 .

Machine B05: position JV2/JV3, 0m to node 62 , length $3186 \mathrm{~m}$ to job 3 Cleaning, position JI4/R-end, $50 \mathrm{~m}$ to node 33. By route 626364405145272933 .

Table 2 Length matrix of the system machine-job

\begin{tabular}{|c|c|c|c|c|}
\hline \multicolumn{5}{|c|}{ Length matrix (m) } \\
\hline \multirow{2}{*}{ Machine } & \multicolumn{3}{|c|}{ Job } & Total length \\
\hline & 1 & 2 & 3 & Machine-Job \\
\hline B03 & 2935 & 4856 & 4985 & \multirow{3}{*}{9781} \\
\hline B05 & 4732 & 5195 & 3186 & \\
\hline A3 & 1739 & 3080 & 3790 & \\
\hline
\end{tabular}

Machine A3: position JII1/L-end $0 \mathrm{~m}$ to node 37, 
length $1739 \mathrm{~m}$ to job1 Construction of route, position JIV3/middle $377 \mathrm{~m}$ to node 8 , by route 37363578 .

II procedure "selection of partner" solution for trajectories system, Tab. 3 .

Length matrix: coupling procedure.

Machine B03: position Containers area, $400 \mathrm{~m}$ to node 3 , length $2935 \mathrm{~m}$ to job1 Construction of route, position $\mathrm{JIV} 3 /$ middle $377 \mathrm{~m}$ to node 8 . By route 345678

Machine B05: position JV2/JV3, $0 \mathrm{~m}$ to node 62, length $3186 \mathrm{~m}$ to job 3 Cleaning, position JI4/R-end $50 \mathrm{~m}$ to node 33. By route 626364405145272933

Machine A3: position JII1/L-end, $0 \mathrm{~m}$ to node 37, length $3080 \mathrm{~m}$ to job 2 Cleaning, position JIV1/R-end $0 \mathrm{~m}$ to node 19. By route 373635252119

Table 3 Length matrix for trajectories system machine-job

\begin{tabular}{|c|c|c|c|c|}
\hline \multicolumn{5}{|c|}{ Length (m) } \\
\hline \multirow{2}{*}{ Machine } & \multicolumn{3}{|c|}{ Job } & Total length \\
\cline { 2 - 4 } & 1 & 2 & 3 & Machine-Job \\
\hline B03 & 2935 & 4856 & 4985 & \multirow{2}{*}{9201} \\
\hline B05 & 4732 & 5195 & 3186 & \\
\hline A3 & 1739 & 3080 & 3790 & \\
\hline
\end{tabular}

Movement of machine A3 from node 37 to 19 is shown in Fig. 9.

III procedure "dictated solution": solution for trajectories system, Tab. 4.

Table 4 Length matrix of the system machine-job

\begin{tabular}{|c|c|c|c|c|}
\hline \multicolumn{5}{|c|}{ Length matrix (m) } \\
\hline \multirow{2}{*}{ Machine } & \multicolumn{3}{|c|}{ Job } & Total length \\
\cline { 2 - 4 } & 1 & 2 & 3 & Machine-Job \\
\hline B03 & 2935 & 4856 & 4985 & \multirow{2}{*}{11920} \\
\hline B05 & 4732 & 5195 & 3186 & \\
\hline A3 & 1739 & 3080 & 3790 & \\
\hline
\end{tabular}

\section{Length matrix: coupling procedure}

Machine B03: position Containers area, $400 \mathrm{~m}$ to node 3, length $2935 \mathrm{~m}$ to job 1 Construction of route, position JIV3/Sred $377 \mathrm{~m}$ to node 8 . By route 345678

Machine B05: position JV2/JV3, $0 \mathrm{~m}$ to node 62, length $5195 \mathrm{~m}$ to job 2 Cleaning, position JIV1/Dend $0 \mathrm{~m}$ to node 19. By route 626364405145272915141719.

Machine A3: position JII1/L-end $0 \mathrm{~m}$ to node 37, length $3790 \mathrm{~m}$ to job 3 Cleaning, position JIV/R-end $50 \mathrm{~m}$ to node 33. By route 3736357891034302933 .

Pursuant to lengths of routes calculated according to procedures I, II and III from position of machines to position of jobs, Tab. 5 has been obtained.

\begin{tabular}{|c|c|c|c|c|}
\hline Procedure & Machine & Job & $\begin{array}{l}\text { Length } \\
(\mathrm{m})\end{array}$ & $\begin{array}{c}\text { Total } \\
(\mathrm{m})\end{array}$ \\
\hline \multirow{3}{*}{ I } & B03 & 2. Cleaning & 4856 & \multirow{3}{*}{9781} \\
\hline & B05 & 3. Cleaning & 3186 & \\
\hline & A3 & 1. Construction of route & 1739 & \\
\hline \multirow{3}{*}{ II } & B03 & 1. Construction of route & 2935 & \multirow{3}{*}{9201} \\
\hline & B05 & 3. Cleaning & 3186 & \\
\hline & A3 & 2. Cleaning & 3080 & \\
\hline \multirow{3}{*}{ III } & B03 & 1. Construction of route & 2935 & \multirow{3}{*}{11920} \\
\hline & B05 & 2. Cleaning & 5195 & \\
\hline & A3 & 3. Cleaning & 3790 & \\
\hline
\end{tabular}

Pursuant to TOTAL LENGTH OF ROUTES (Tab. 5) from position machine to position jobs:

- according to procedure I it is: $9781 \mathrm{~m}$,

- according to procedure II it is: $9201 \mathrm{~m}$,

- according to procedure III it is: $11920 \mathrm{~m}$,

It is concluded that the "shortest" - optimum length of the systems Machine and Jobs has been obtained from procedure II, i.e. from procedure "selection of partner" it is: $9201 \mathrm{~m}$.

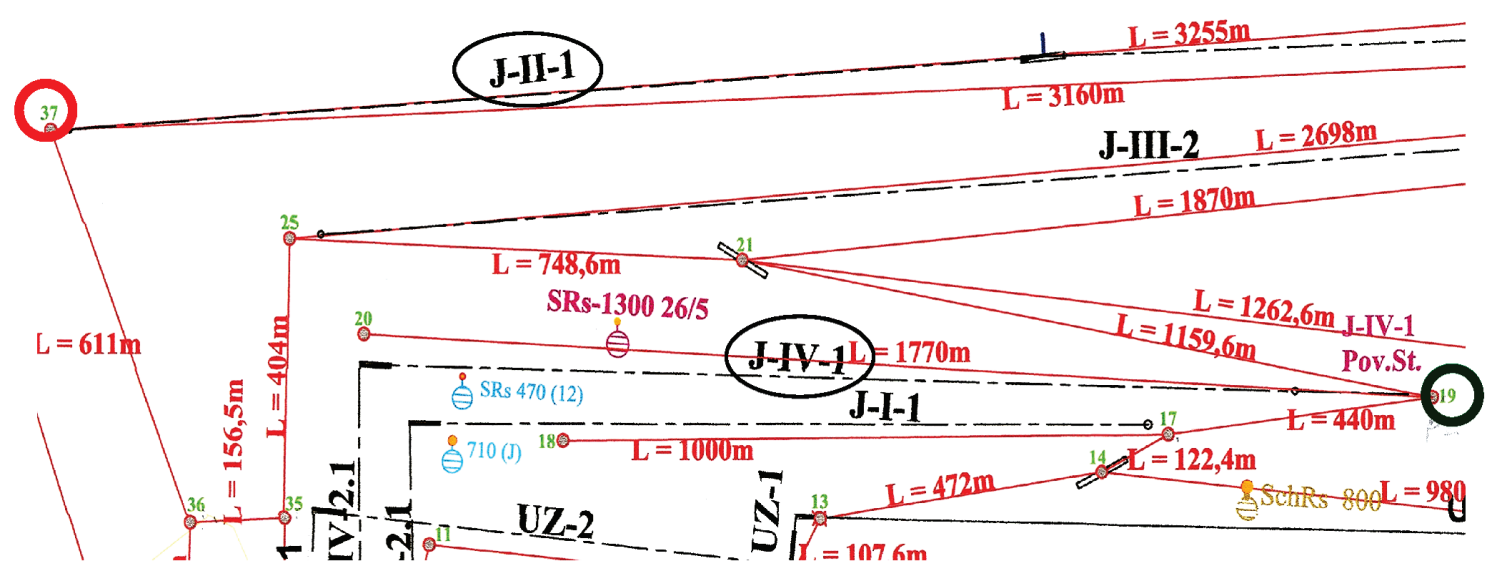

Figure 9 Machine A3: position JII1/L-end, 0.m to node 37, length 3080m to job 3, position JIV1/D-end Om to node 19 By route 373635252119 (top part Fig. 4)

\section{CONCLUSION}

Optimization of machine movement trajectory at the open-pit coal mine has been conducted as a result of developed software application Machine Trajectories based on GPS/GPTRS technologies for accurate positioning of machine at the open-pit and local map with marked routes and nodes (passages above and below conveyor belts, redirection of routes).

As presented in the example, there is each individual solution "one machine for one job". However, if we observe more than one machine of the same type which have to perform the same job (from the scope of jobs of this type of machines, e.g. bulldozer) then the shortestoptimum route of all machines and all jobs is determined 
by the smallest sum of the route lengths within the machines and jobs system. In addition to the route length, this optimum length of the route also results in other benefits. Machine transportation time is shortenedoptimized from machine position to job position, as well as the fuel consumption of these machines. Therefore, owing to optimization of trajectory from machine(s) to job(s), significant quantities of fuel have been saved.

\section{Acknowledgements}

Research presented in this paper has been conducted within the project TR 35030 which is supported by technological development programme of the Ministry of Education, Science and Technological Development of the Republic of Serbia.

\section{REFERENCE}

[1] Ivanovic, G., Pantelic, S., Skataric, D. et al. (2015). Development and implementation of the management system operational activities auxiliary machinery based on the availability and production of economic indicators of operational work to support modern information systems / information technology, Phase I, II, III, Faculty of Mechanical Engineering in Belgrade, Report no MF 09.03376/11, 09.03-381/12,09.03-393/15, Belgrade, 2011-2015.

[2] Ivanović, G., Stošić, D. Skataric, D. et al. (2013). GPS/GPRS system auxiliary machinery TE-KO Kostolac, Faculty of Mechanical Engineering in Belgrade, Report no MF 09.03415/13, Belgrade.

[3] Pantelic, S., Ivanovic, G. Mitrovic, R., Jovanovic, D., Stosic, D., \& Dimitrijevic S. (2013). Improvement of Auxiliary Mechanization Operations Management at an Open-Pit Coal Mine Based on a Process Approach with ICT Support. Advances in Engineering Materials, Product and Systems Design, Advanced Materials Research, 633, 322-324. https://doi.org/10.4028/www.scientific.net/AMR.633.322

\section{Contact information:}

Milos IVANOVIC, master el.

Faculty of Mechanical Engineering,

University in Belgrade,

Kraljice Marije 16, 11000 Beograd, Serbia

E-mail: givanovic@mas.bg.ac.rs

Dobrila SKATARIC, prof. dr

Faculty of Mechanical Engineering,

University in Belgrade,

Kraljice Marije 16, 11000 Beograd, Serbia

E-mail: dskataric@mas.bg.ac.rs 